\title{
Factors determining parents' perception of their child's risk of life-threatening food-induced anaphylaxis
}

DOI:

10.2500/aap.2017.38.4002

10.2500/aap.2017.38.4002

\section{Document Version}

Proof

Link to publication record in Manchester Research Explorer

\section{Citation for published version (APA):}

Ogg, J., Wong, J., Wan, M., Davis, N., \& Arkwright, P. (2017). Factors determining parents' perception of their child's risk of life-threatening food-induced anaphylaxis. Allergy and Asthma Proceedings, 38(1).

https://doi.org/10.2500/aap.2017.38.4002, https://doi.org/10.2500/aap.2017.38.4002

\section{Published in:}

Allergy and Asthma Proceedings

\section{Citing this paper}

Please note that where the full-text provided on Manchester Research Explorer is the Author Accepted Manuscript or Proof version this may differ from the final Published version. If citing, it is advised that you check and use the publisher's definitive version.

\section{General rights}

Copyright and moral rights for the publications made accessible in the Research Explorer are retained by the authors and/or other copyright owners and it is a condition of accessing publications that users recognise and abide by the legal requirements associated with these rights.

\section{Takedown policy}

If you believe that this document breaches copyright please refer to the University of Manchester's Takedown Procedures [http://man.ac.uk/04Y6Bo] or contact uml.scholarlycommunications@manchester.ac.uk providing relevant details, so we can investigate your claim.

\section{OPEN ACCESS}




\title{
Allergy \& Asthma Proceedings
}

\author{
Post-Acceptance check list \\ Editor-in-Chief \\ Joseph A Bellanti, MD \\ Professor of Pediatrics and Microbiology-Immunology \\ Georgetown University Medical Center \\ Washington, DC 20057
}

OceanSide Publications 450 Veterans Memorial Parkway, Bldg. 15 East Providence RI 02914

Phone (401) 331-2510 Fax (401) 331-0223 oceanside@oceansidepubl.com

\section{The following checklist must be completed before we can schedule the publication of your paper:}

$\checkmark$ Publication forms: A complete set of forms (copyright AND conflict of interest) must be on file for each author listed. These must be submitted if not yet done so - blank forms are attached. Please note that it is the intent of the publisher to publish ONLY information regarding potential conflicts of interest which are relevant and related to the products or disease states discussed in the manuscript. It is very important that you do not provide conflicts which are unrelated to the subject matter so that publication of non-relevant information can be avoided.

$\checkmark$ Completed forms may be sent to compliance@oceansidepubl.com .

$\checkmark$ Color preference: If your paper contains color figures, these will publish in color in the online version of the AAP at no cost. If your manuscript is selected to be print published in addition to online, please contact the editorial office via email if you desire to have your figures to print in color as there are additional costs for which you would be responsible. (compliance@oceansidepubl.com)

$\checkmark$ Author queries: Please respond to all author queries within the requested time. Most importantly, review the Author Query regarding the conflict statement in the footnote and confirm that what is listed is correct and limited strictly to only that which is relevant to your paper.

$\checkmark$ Reprint requests: the following pages contain a reprint request form, the use of which is limited to the non-commercial needs of the author. Please confirm that all payment information is correct, and mailing instructions are accurate.

$\checkmark$ For commercial reprints, contact Beth Ann Rocheleau (brocheleau@rockwaterinc.com)

Once you have completed the above checklist and answered all the author queries, send all author responses to Denise Altland as instructed via email (Denise.Altland@cenveo.com ) or fax ((877) 705-1381.

Any publishing forms, color preferences, and reprint requests should be sent to compliance@oceansidepubl.com . 


\section{OceanSide Publications, Inc ${ }_{11.14}$}

MEDICAL PUBLISHERS

450 Veterans Memorial Parkway, Bldg. 15

EAST PROVIDENCE, RHODE ISLAND 02914

Phone: (401) 331-2510 Fax: (401) 331-0223

\section{CHOOSE JOURNAL:}

$\square$ Allergy and Asthma Proceedings $\quad \square$ American Journal of Rhinology and Allergy

$\square$ Allergy \& Rhinology

AUTHOR(S):

TITLE OF ARTICLE:

Reference:

VOLUME NUMBER

ISSUE NUMBER

MONTH/YEAR

- Orders accepted in multiples of 100 only.

- Minimum order is 100 reprints.

- The author reprint prices are only available to non-commercial authors. For commercial reprints, please contact Beth Rocheleau at brocheleau@rockwaterinc.com

\section{REPRINT PRICE LIST}

Black \& White Reprints (Contact OceanSide for color reprint prices.)

\begin{tabular}{|c|c|c|}
\hline & \multicolumn{2}{|c|}{ Number of Copies } \\
\hline Pages & $\mathbf{1 0 0}$ & $\mathbf{2 0 0}$ \\
\hline $1-4$ & $\$ 206$ & $\$ 306$ \\
\hline $5-8$ & $\$ 427$ & $\$ 607$ \\
\hline $9-12$ & $\$ 623$ & $\$ 895$ \\
\hline $13-16$ & $\$ 815$ & $\$ 1179$ \\
\hline $17-20$ & $\$ 1018$ & $\$ 1462$ \\
\hline $21-24$ & $\$ 1214$ & $\$ 1750$ \\
\hline $25-58$ & $\$ 1414$ & $\$ 2043$ \\
\hline $29-32$ & $\$ 1613$ & $\$ 2335$ \\
\hline
\end{tabular}

\section{PREPAYMENT IS REQUIRED FOR ALL ORDERS}

Reprints, (no covers). Quantity Amount

Plain/Blank White Covers $(\$ 22.00 / 100)$. Quantity Amount or Printed Covers (Title and author listed):

First 100/\$111.00 Quantity Amount

Each additional 100/\$24.00. Quantity Amount

Foreign shipping and handling. $\$ 125.00$

Total amount due 


\section{Complete the below information, print clearly:}

BILLING INSTRUCTIONS:

Send invoice to:

\section{SHIPPING INSTRUCTIONS:}

Please type or print all information below:

Ship reprints to:

PHONE:

IMPORTANT!! Please include phone and/or fax number to expedite shipping.

E-MAIL ADDRESS:

SIGNATURE:

By signing this form the author agrees to accept responsibility for the payment of the reprints and/or all charges referred to on the reverse side of this document. If charges are to be billed to an institution, the author assumes the responsibility for making the necessary arrangements for the issuance of a formal institutional purchase order. Otherwise, it is understood that the author will bear the cost of this reprint order.

\section{CREDIT CARD AUTHORIZATION:}

If you would like to charge the reprints to your credit card (Visa, MasterCard, or American Express), please provide the information below. The credit card receipt will be included in the box with the reprints.

Card Number: Expiration date:

Signature of Cardholder:

Please fax to $401-331-0223$ or mail to:

OceanSide Publications, Inc.

Attn: Reprint Request

450 VETERANS MEMORIAL PARKWAY, BLDG. 15

EAST PROVIDENCE, RI 02914 


\title{
AUTHORS' COPYRIGHT ASSIGNMENT AND RELEASE
}

\section{ALLERGY AND ASTHMA PROCEEDINGS}

\author{
OceanSide Publications, Inc. \\ 450 Veterans Memorial Parkway, Bldg.15 \\ East Providence, RI 02914 USA
}

(Each author listed on the title page must complete and return this form at the time of manuscript submission.)

In consideration of OceanSide Publications, Inc. (“OceanSide”) evaluating the manuscript, including all tables, graphs, and photos which form a part thereof, entitled,

(Manuscript number \# AAP ), hereafter referred to as the "Work," for publication in the Allergy and Asthma Proceedings and possibly publishing the Work, the undersigned author(s) hereby grant and assign to OceanSide Publications, Inc. (“OceanSide”) the entire copyright, under United States and international law, in and to the Work. This includes the exclusive right to publish, republish, reproduce, prepare derivative works of, transmit, sell, distribute copies, by sale or otherwise, renew copyright in, perform, and display the Work in all languages and forms of media worldwide, and to license or permit others to do so, effective if and when it is accepted for publication in Allergy and Asthma Proceedings .

The authors hereby represent and warrant by their signature below that (i) all portions of the Work are either our own original creations or material for which we have obtained all necessary consents for the use, distribution, and publication of such materials; (ii) the content of the Work is accurate to the best of our knowledge and does not violate any copyright, proprietary or personal rights of others; (iii) the materials, including photographs, that are part of the Work do not identify, by name or otherwise, suggest the identity of, or present a recognizable likeness of any patient or others; or, if they do, we have obtained all necessary consents from patients and others for the further use, distribution, and publication of such materials; (iv) the Work does not contain anything libelous or illegal, and does not infringe on the rights (including the copyright, patent or trademark rights) or the privacy of others; (v) the Work, nor a similar manuscript, has not previously been published (except in abstract form); and is not currently under consideration by another journal and (vi) we have not granted other parties any rights in or to the Work, which are inconsistent with the rights herein granted to OceanSide; this Work is not currently under consideration by another journal and we will not submit the Work for publication elsewhere while it is under consideration by Allergy \& Asthma Proceedings. We hereby acknowledge that OceanSide will be relying on this Authors' Copyright Assignment and Release if the Work is published.

If the work was prepared jointly, it is our responsibility, as authors, to inform all co-authors of the terms of this agreement and that they must also sign this agreement. If the Work was written by an author in the course of the author's employment, the employer/company (Institution) has been informed of the terms of this agreement by the author. In such case, by the signature below, the author, acting as an agent of the employer/company (Institution), conveys the employer's/company's (Institution's) assignment to OceanSide, of all copyright in and to the Work for the full term of the copyright throughout the world as specified in the paragraph above.

The authors hereby indemnify and hold harmless OceanSide, the regional, state and local allergy societies and the American Association of Certified Allergists ("AACA"), and their respective officers, directors, members, employees and agents from and against any and all claims, losses, demands, costs (including reasonable attorneys' fees), and other expenses arising directly or indirectly from the inaccuracy or breach of any of the aforementioned representations, covenants and warranties.

The authors understand and acknowledge that OceanSide undertakes no obligation to publish the Work. If it is published, OceanSide will acknowledge our participation, but we will receive no compensation and no other benefit with respect to the Work. OceanSide shall return all rights herein granted by the authors upon written request if the Work is not published within eighteen (18) months of the date of this Authors' Copyright Assignment and Release.

$\operatorname{Rev} 1 / 2013$ 
Note: The Editor may refuse to consider manuscript submissions from any author who has previously had a manuscript rejected by Proceedings for reasons of plagiarism, undisclosed conflicts-of-interest, inappropriate authorship, fraud, or duplicate publication.

Signature:

Date:

Printed name:

Signature:

Date:

Printed name:

Signature:

Date:

Printed name:

Signature:

Date:

Printed name:

Signature:

Date:

Printed name:

Signature:

Date:

Printed name:

Authors on multi-authored manuscripts have the option of submitting this agreement individually; however the review process will not commence until all signatures are received. Forms may be mailed to the above address, emailed, or faxed to the number below.

FAX: 401-331-0223

Email : compliance@oceansidepubl.com 


\title{
Allergy \& Asthma Proceedings
}

\author{
Oceanside Publications 450 Veterans Memorial Parkway, Bldg. 15 East Providence RI 02914 \\ Phone (401) 331-2510 Fax (401) 331-0223 \\ e-mail: compliance@oceansidepubl.com
}

\section{Conflict of Interest}

The purpose of this form is to provide readers of your manuscript with information about your other interests that could influence how they receive and understand your work. Please note the Journal seeks only information which relates to your manuscript. If your manuscript is accepted for publication, your relevant disclosures will be published as a footnote. Please indicate if you or your institution received funds from a third party to support the work, such as a Government granting agency, charitable foundation or commercial sponsor. This support may include grants, consulting fees, honorariums, travel reimbursement, fees for manuscript data review or writing and provision of writing assistance, medicines, equipment, or administrative support. Please report all sources, relevant to the submitted work, of revenue paid (or promised to be paid) directly to you or your institution on your behalf over the 36 months prior to submission of the work. This support may include board memberships, consultancies, employment, expert testimony, grants, speaker's bureaus, payment for manuscript preparation, patents, royalties, creation of educational pieces, stocks, stock options, and other support. Please do not provide disclosure regarding sources which do not have relevance to the submitted work. Please report grants you have received for work outside the submitted work. You should disclose support ONLY from entities that could be perceived to be affected financially by the published work, such as pharmaceutical companies, or foundations supported by entities that could be perceived to have a financial stake in the outcome. Public funding sources, such as government agencies, charitable foundations or academic institutions, need not be disclosed. Finally, please report other relationships or activities that readers could perceive to have influenced, or that give the appearance of potentially influencing what you wrote in the submitted work.

Name of Author:

Address:

Manuscript Title:

Manuscript \#:

Check One:

( ) I have no actual or potential conflict of interest in relation to this paper.

Signature: Date:

OR

( ) I have a financial interest/arrangement or affiliation with one or more organization(s) that could be perceived as a real or apparent conflict of interest in the subject of this paper. Please complete the attached Conflict of Interest worksheet with all information RELEVANT to the work submitted.

Note: Each author listed on the title page must complete and return this form prior to publication.

Paperwork may be submitted via email to compliance@oceansidepubl.com

OR faxed to (401) 331-0223

OR uploaded as a supplement file to your manuscript via http://aap.msubmit.net

OR mail to:

OceanSide Publications, Inc.

450 Veterans Memorial Parkway, Bldg. 15

East Providence, RI 02914 USA

Phone 401.331.2510

Fax 401.331.0223

E-mail compliance@oceansidepubl.com 


\section{Allergy \& Asthma Proceedings}

Oceanside Publications 450 Veterans Memorial Parkway, Bldg. $15 \sim$ East Providence RI 02914

Phone (401) 331-2510 Fax (401) 331-0223

e-mail: compliance@oceansidepubl.com

Author name:

\section{Conflict of Interest Worksheet}

Manuscript \#: AAP

Section 1: Potential Conflicts of Interest related to the work under consideration for publication:

\begin{tabular}{|l|l|l|l|}
\hline \multicolumn{1}{|c|}{ Type } & $\begin{array}{l}\text { Provided to } \\
\text { you or your } \\
\text { institution* }\end{array}$ & Comments & Name of Entity \\
\hline 1. Grant & & & \\
\hline 2. Consulting fee or honorarium & & & \\
\hline $\begin{array}{l}\text { 3. Support for travel to meetings for the } \\
\text { study or other purposes }\end{array}$ & & & \\
\hline $\begin{array}{l}\text { 4. Fees for participation in review } \\
\text { activities such as data monitoring } \\
\text { boards, statistical analysis, end } \\
\text { point committees, and the like }\end{array}$ & & & \\
\hline $\begin{array}{l}\text { 5. Payment for writing or reviewing } \\
\text { the manuscript }\end{array}$ & & & \\
\hline $\begin{array}{l}\text { 6. Provision of writing assistance, } \\
\text { medicines, equipment, or } \\
\text { administrative support }\end{array}$ & & & \\
\hline 7. Other & & & \\
\hline
\end{tabular}

*Simply place an "X". Do not provide dollar amounts.

Section 2: Relevant financial activities outside the submitted work

\begin{tabular}{|c|c|c|c|}
\hline Type of Relationship & $\begin{array}{l}\text { Provided to } \\
\text { you or your } \\
\text { institution* }\end{array}$ & Name of Entity & Comments \\
\hline \multicolumn{4}{|l|}{ 1. Board membership } \\
\hline \multicolumn{4}{|l|}{ 2. Consultancy } \\
\hline \multicolumn{4}{|l|}{ 3. Employment } \\
\hline \multicolumn{4}{|l|}{ 4. Expert testimony } \\
\hline \multicolumn{4}{|l|}{ 5. Grants/grants pending } \\
\hline \multicolumn{4}{|l|}{$\begin{array}{l}\text { 6. Payment for lectures including } \\
\text { service on speakers bureaus }\end{array}$} \\
\hline \multicolumn{4}{|l|}{ 7. Payment for manuscript preparation } \\
\hline \multicolumn{4}{|l|}{ 8. Patents (planned, pending or issued) } \\
\hline \multicolumn{4}{|l|}{ 9. Royalties } \\
\hline \multicolumn{4}{|l|}{$\begin{array}{l}\text { 10. Payment for development of educational } \\
\text { presentations }\end{array}$} \\
\hline \multicolumn{4}{|l|}{ 11. Stock/stock options } \\
\hline \multicolumn{4}{|l|}{$\begin{array}{l}\text { 12. Travel/accommodations/meeting expenses } \\
\text { unrelated to activities listed** }\end{array}$} \\
\hline 13. Other (err on the side of full disclosure) & & & \\
\hline
\end{tabular}

*Simply place an "X". Do not provide dollar amounts.

\section{Section 3: Other relationships}

Are there other relationships or activities that readers could perceive to have influenced, or that give the appearance of potentially influencing, what you wrote in the submitted work?

$\square \quad$ Yes, the following relationships/conditions/circumstances are present (explain below):

No other relationships/conditions/circumstances that present a potential conflict of interest

** At the time of manuscript acceptance, journals will ask authors to confirm and, if necessary, update their disclosure statements. On occasion, journals may ask authors to disclose further information about reported relationships. 


\section{Adding Comments to Your PDF}

The PDF provided has been "comment enabled," which allows you electronically mark your PDF with your requested changes. To facilitate electronic transmittal of corrections, we ask all authors to use the annotation tools available in the Comment Menu of Adobe Reader and Adobe Professional. Adobe Reader can be downloaded for free (acceptable versions X or XI; DC is not compatible at this time).

To access the Comment Menu, you should select "Comment" in the upper right corner of the screen.

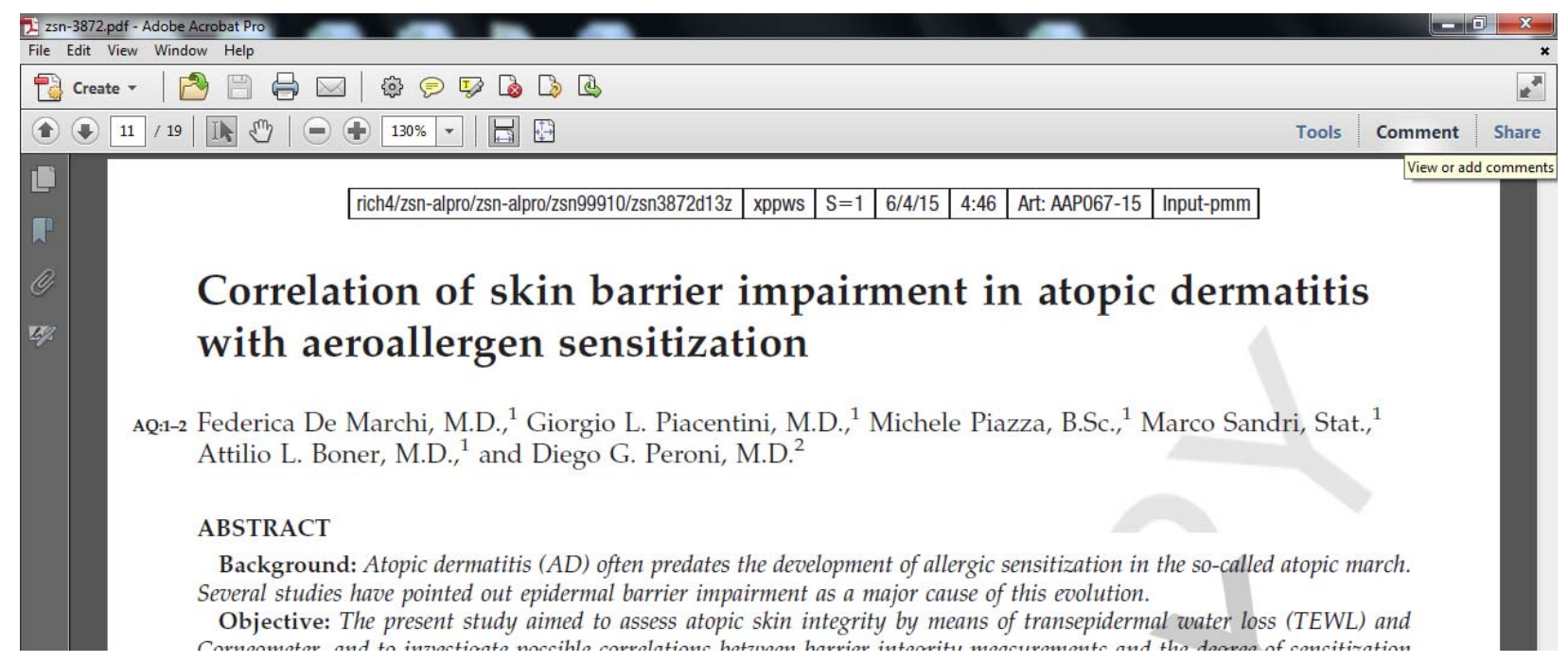

Once the Comment Menu has been opened, you will find the annotation and drawing markup tools. We recommend that you use the annotation tools whenever possible, limiting the use of the drawing markup tools.

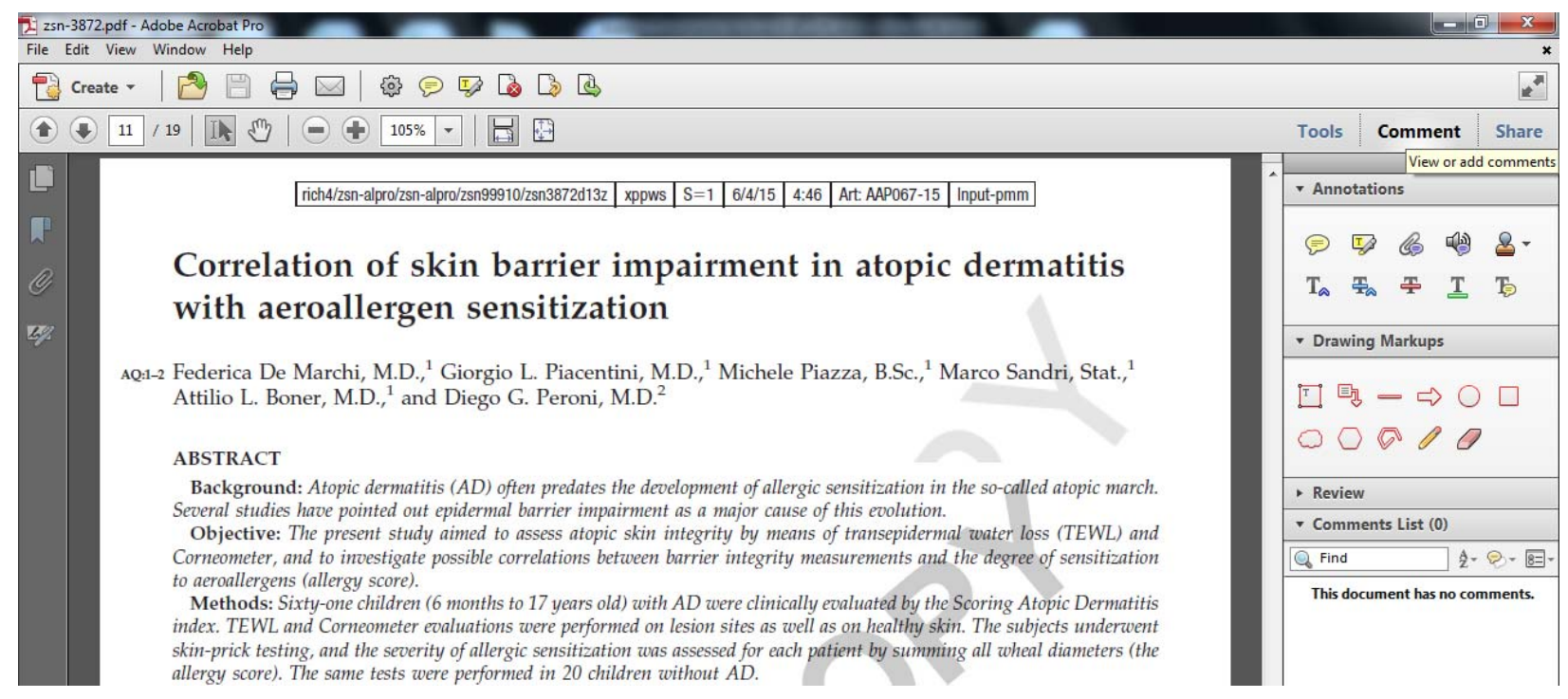


You may begin marking your PDF with your requested changes. Please note that your corrections will not be made automatically. Once you are finished marking the changes, please select "finalize" to move your corrections to the next stage of production. If you have started making changes but need to save those changes, select the "publish comments".

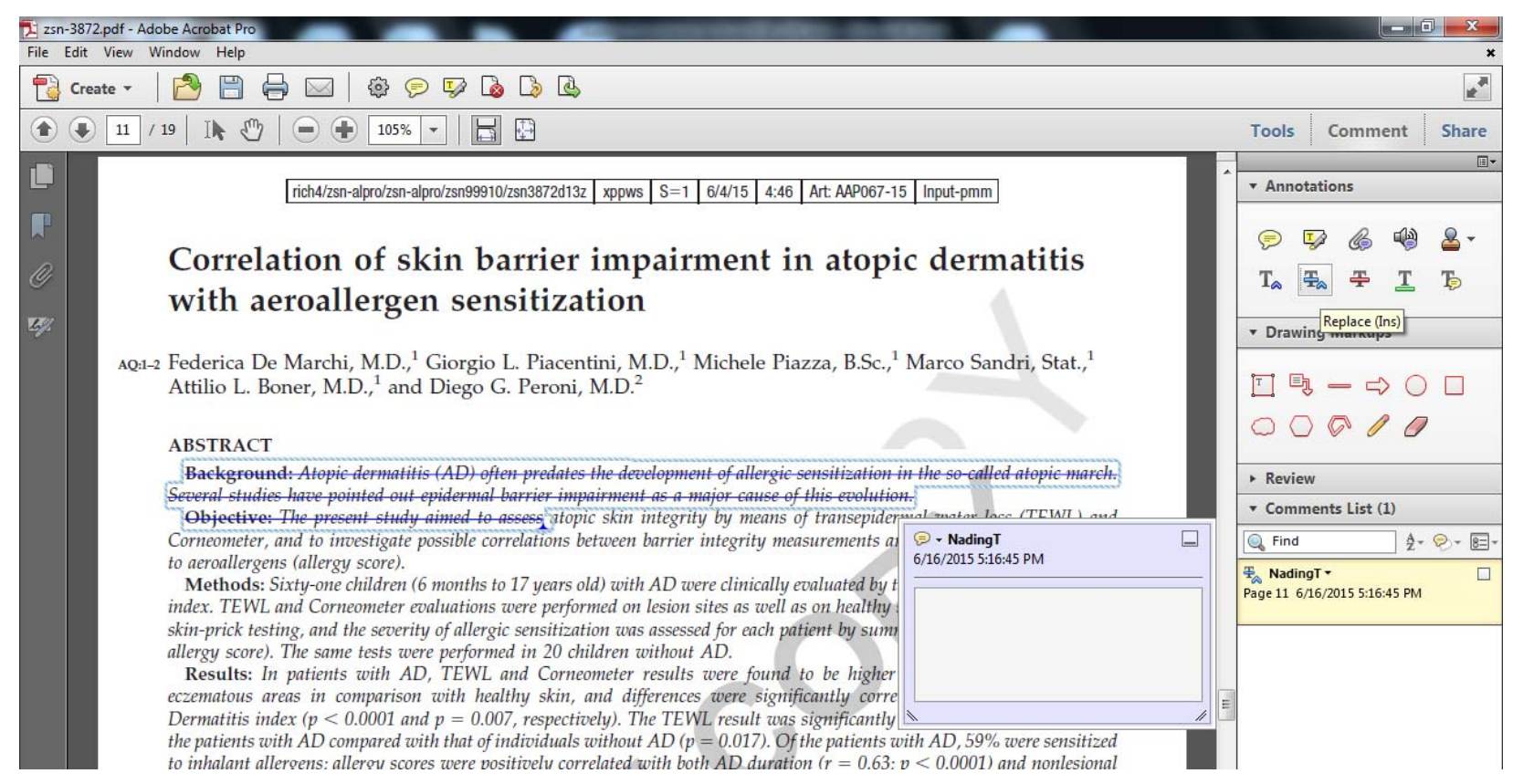

\section{Annotation Tools}

The Comment Bubble is an acceptable tool to use for general/global changes required in the proof. It is not recommended for individual changes as comment bubbles have the tendency to shift location.

The Highlight Text tool should also be used sparingly. We recommend using the Highlight + Comment tool to provide more information to the production team regarding your changes.

T)

Highlight + Comment tool, as mentioned above. This tool can be used to indicate sections of text that should be treated in a certain way; for example, changing roman fonts to bold or italic.

$\mathrm{T}_{\mathbf{Q}}$

The Insert Text tool should be used to insert missing characters or text. Place your curser in the location where the text should be added and select this tool. 
The Crossout + Insert tool should be used whenever you want to replace one word with another. This tool can also be used on large sections of text. Highlight the text you want changed, select this tool and start typing.

The Crossout (Only) text tool. Highlight the text you want deleted and select this tool.

T

The Underline tool. While this is an acceptable tool to use, we recommend that if you need words italicized or emphasized in another way that you use the Highlight + Comment tool instead.

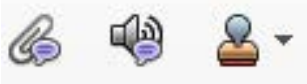

The Attach File, Record Audio, and Stamp tools should not be used. Any additional files can be submitted to the production team via email.

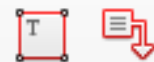

The Insert Text Box and Add Text Callout tools are acceptable drawing markup tools to use, but the tools mentioned above (Insert Text and Crossout + Insert) are highly recommended for faster correction processing.

The other tools in Drawing Markups should be used sparingly. 


\title{
Factors that determine parents' perception of their child's risk of life-threatening food-induced anaphylaxis
}

AQ: 1 Jennifer Ogg, M.B.B.Ch., ${ }^{1}$ Jayne Wong, M.B.B.Ch., ${ }^{1}$ Ming Wai Wan, Ph.D., ${ }^{2}$ Naomi Davis, M.D., ${ }^{3}$ and Peter D. Arkwright, M.D., Ph.D. ${ }^{1}$

\begin{abstract}
Background: Although food allergy is known to be associated with increased disease burden, factors that shape parents' perception of their child's risk of future severe or fatal anaphylaxis are poorly understood.

Objective: This study aimed to evaluate factors associated with parents' perceived risk of food-induced anaphylaxis.

Methods: A questionnaire-based survey of 202 parents was conducted in a single specialist center outpatient clinic that treats children with food allergies. Parents' perceived risk of their child experiencing further food-induced anaphylaxis was assessed by using a validated food allergy independent measure. Demographic data as well as parents' anxiety and depression scores were assessed by using the Hospital Anxiety and Depression score.

Results: Nineteen percent of parents believed that their child had a moderate-to-high chance of dying from food-induced anaphylaxis. A lack of a university education, higher anxiety score, and, particularly, possession of an epinephrine autoinjector (relative risk 9.9 [95\% confidence interval, 3.3-30]) were key factors associated with heightened risk perception. Caring for a child with multiple food allergies was the main factor associated with parents feeling less able to manage future reactions AQ: 2 Delative risk 9.5 [95\% confidence interval, 1.7-53]). Parents' risk perception of fatal anaphylaxis correlated with anxiety and mood scores.
\end{abstract}

Conclusion: Parents' education, affect, and possession of an epinephrine autoinjector were associated with a heightened perceived risk of future anaphylaxis. Clinicians should consider not only the child's needs but should also provide counseling for parents, particularly those who possess autoinjectors. Parents of children with multiple food allergies may need additional education and training to help them cope with future reactions.

(Allergy Asthma Proc 37:1-10, 2016; doi: 10.2500/aap.2016.37.4002)

$\mathbf{F}^{\mathrm{ata}}$ ood allergy is common, occurring in $\sim 8 \%$ of children in Western societies. Although there has been a sixfold increase in hospital admissions for foodinduced anaphylaxis over the past 2 decades, ${ }^{2,3}$ deaths from anaphylaxis remain rare. ${ }^{4,5}$ Two concerns of both patients and their caregivers are the child's risk of future anaphylaxis and their ability to effectively manage future reactions. Anxiety has a negative impact on quality of life (QoL) of both the patient and his or her family. Over the years, many guidelines have been published with the aim of reducing anxiety and engendering patient and caregiver confidence by providing

\footnotetext{
AQ: 2 F m the Institute of Inflammation and sity of Manchester, Manchester, United Kingdom, and ${ }^{3}$ Departm 2 Paediatric Orthopaedic Surgery, Royal Manchester Children's Hospital, Manchester, United AQ: 23 study was funded solely by the University of Manchester

study was funded solely by the University of Manchester
D. Arkwright has received financial assistance from both Meda Pharmaceuticals Ltd and ALK-Abello to attend scientific conferences and from Bausch \& Lomb for consulting. The remaining authors have no conflicts of interest pertaining to this article Address correspondence to Peter D. Arkwright, M.D., Department of Paediatric Allergy and Immunology, University of Manchester, Royal Manchester Children's Hospital, Oxford Rd., Manchester, M13 9WL, United Kingdom

AQ: 2 E ail address: peter.arkwright@nhs.net

yright (C) 2016, OceanSide Publications, Inc., U.S.A.
}

information and advice on the management of allergies. $^{6-16}$

Addressing the key factors associated with heightened levels of a patient's and caregivers' anxiety would reduce the overall disease burden. ${ }^{17,18}$ Although a number of previous studies sought to determine the nature of these factors, conclusions have been quite diverse. For example, a European study of 244 children with food allergy found that allergen type and nationality but not history of previous reactions or possession of an epinephrine autoinjector (EAI) were important in determining health-related QoL. ${ }^{19}$ A U.S. survey of 305 caregivers concluded that a Food Allergy Quality of Life-Parental Burden index was affected by not only allergen type but also the number of allergens, patient's age, parental income, and history of reactions. ${ }^{20}$ A follow-up study of 3541 caregivers by the same U.S. group administered through social media reinforced these findings and indicated that QoL was better in parents of children who had received epinephrine for previous anaphylactic reactions, possibly by increasing the confidence of families that future reactions would be managed successfully. ${ }^{21}$ Cummings $e t$ al. ${ }^{22}$ indicated that there was reduced anxiety in children and parents who possessed an EAI, but their study was small and only included five parents who had no EAI. In con- 
Table 1 Comparative questions in the questionnaire handed out to parents of children with food allergies and parents of children with injuries

\section{FAIM Questionnaire}

Accidental Injury Questionnaire

Parents' Perceived Risk

Stem

The following questions are about the chance that you think something may happen to your child because of his or her food allergy; choose one of the answers provided; answer the questions by putting an " $X$ " in the box next to the appropriate answer

Questions

Chance that your child will accidentally eat something to which he or she is allergic?

Chance that your child will have a severe reaction if her or she eats something to which he or she is allergic?

Chance that your child will die if he or she accidentally eats something to which he or she is allergic?

Chance that you will not be able to effectively deal with an allergic reaction should your child accidentally eat something to which he or she is allergic?
Stem

The following questions are about the chance that you think something may happen to your child because of another accidental injury; choose one of the answers provided; answer the questions by putting an " $X$ " in the box next to the appropriate answer

Questions

Chance that your child will have another injury?

Chance that your child will have a severe injury that needs a plaster cast or operation?

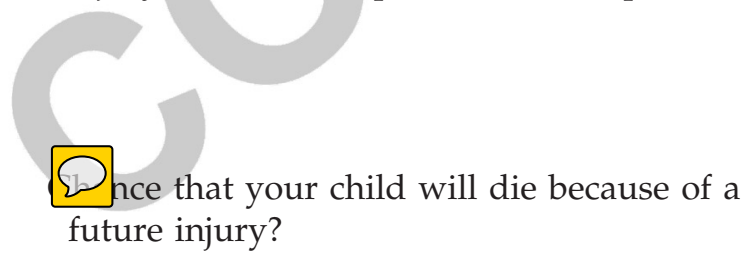

Response: Never ( $0 \%$ chance), very small chance, small chance, fair chance, great chance, very great chance, always $(100 \%$ chance)

Impact on Child's Life

Questions

How great is the impact of your child's food allergy on his or her school life?

How great is the impact of your child's food allergy on his or her activities outside school?

Questions

How great is the impact of your child's injury on his or her school life?

How great is the impact of your child's injury on his or her activities outside of school?

Response: Almost none, very small, small, moderate, great, very great, extremely great

FAIM $=$ Food Allergy Independent Measure.

Differences in wording between the two questionnaires are highlighted.

trast, an Australian survey found that QoL of 167 caregivers assessed by using the Food-Allergy Quality of Life scale was poorer in those caregivers who possessed an EAI. ${ }^{23}$ A subgroup of parents of children with food allergies, therefore, may benefit from additional support from health care professionals. ${ }^{24}$

The aim of this study was to dissect out key psychological and physical factors associated with heightened parental perception of future anaphylaxis. As well as measuring levels of anxiety and depression, obsessivecompulsive tendencies of the parents were also assessed because we had previously observed a propensity to this personality trait in families with severe food allergies and atopic dermatitis. ${ }^{25}$ We hypothesized that a combination of demographic and psychological factors would be associated with parents' risk perception. Primeau et $a l .{ }^{8}$ found that caring for a child with peanut allergy was a greater disruption to family life than caring for a child with other diseases, e.g., arthritis. In this study, we compared the relative impact of a child with food allergy on parents' future risk perception with a group of children who had sustained accidental bony injuries and who were attending an adjoining fracture clinic. Accidental injuries, although not usually chronic, are similar to food-induced anaphylaxis in that they are unpredictable and a cause of concern for most parents. Inclusion of this group allowed for a direct comparison of parents' perceived risk of serious 
adverse events or death of their child with either food allergies, which are rarely fatal, and accidental injuries, the most common cause of death in school-age children.

\section{METHODS}

\section{Study Design}

This was a prospective, questionnaire-based study. The study had local ethics committee approval from the National Research Ethics Service, Liverpool Central Committee; all the parents provided informed written consent. Data sets were complete for all the participants, and no parents withdrew from the study. J. Ogg and J. Wong contributed equally to the study.

\section{Patient Recruitment}

Participants in the allergy group were recruited from parents of consecutive children who attended a specialist pediatric allergy outpatient clinic for assessment and management of food allergies. Clinicians at our specialist pediatric allergy service and throughout the northwest of England prescribe EAI if patients have a clinical history of anaphylaxis (respiratory or circulatory symptoms $)^{26}$ to a food in which future avoidance is likely to be difficult (particularly peanut and tree nuts) or asthma is not controlled with low-dose inhaled steroids. Participants in the injury group were recruited from parents of children who attended an adjoining specialist pediatric fracture clinic for assessment and management of fractures and other bony injuries. Children who attended the fracture clinic and who had a history of food allergy, atopic dermatitis, asthma, or hay fever, or of chronic diseases that predisposed them to fractures were excluded from the study.

\section{Data Collection}

Parents were invited to complete a four-page standardized questionnaire. The questionnaire covered family demographics and details of the child's food allergy or injury. Parents' education and vocation were also recorded. Parental perceptions of the risk of future allergic reactions as well as information about disruption to daily life were collected by using the validated Food Allergy Independent Measure. ${ }^{27}$ A comparable questionnaire was used for parents with children who sustained injuries (Table 1). Anxiety and depression scores were measured by using the Hospital Anxiety and Depression Scale. ${ }^{28,29}$ Obsessive-compulsive tendencies were measured by using the Obsessive-Compulsive Inventory-Revised. ${ }^{30}$

\section{Statistical Analysis}

Data from questionnaires were collated and anaAQ: 4 lyzed by using IBM SPSS Statistics. Continuous vari-

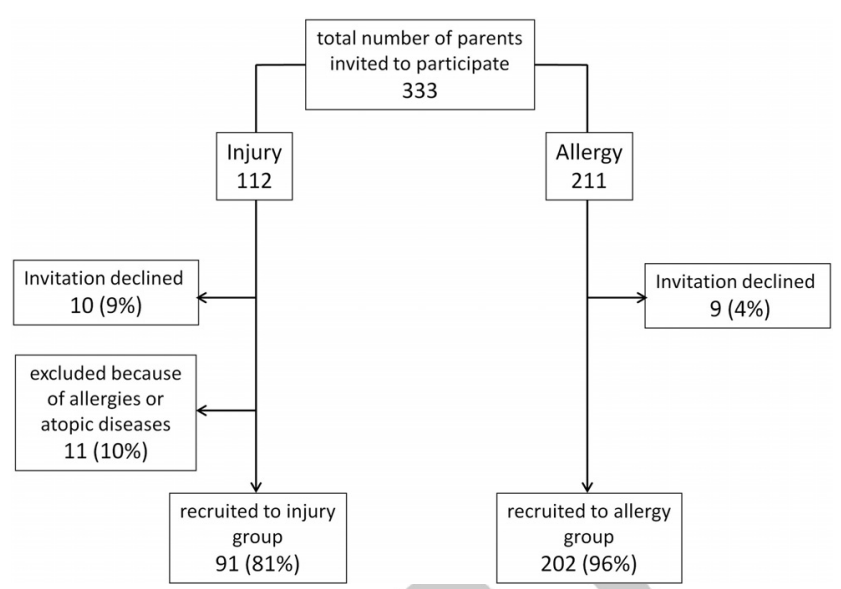

Figure 1. Details of the number of participants invited and enrolled in the study.

ables were displayed as median and interquartile range. Statistical differences between groups were calculated by using either the $\chi^{2}$ test for discrete variables or Mann-Whitney $U$ and Kruskal-Wallis tests for continuous variables. Potential confounding effects of multiple variables were assessed by using binomial regression multivariate analysis. Two-tailed $p$ values of $<0.05$ were considered statistically significant unless otherwise stated.

\section{RESULTS}

\section{Demographic and Clinical Features of Children with Food Allergies and Their Parents}

A total of 333 parents of children who attended outpatient clinics at a single tertiary pediatric hospital were invited to take part in the study. Two hundred and eleven were parents whose children had a history of food allergy and who attended the specialist pediatric allergy clinic. Of these 211 parents, nine (4\%) declined the invitation to participate, which gave a recruitment rate to this part of the study of $96 \%$. From an adjoining orthopedic clinic, a further 112 parents of children who had sustained injuries were also invited to take part as a comparison group. Ten (9\%) declined, and 11 were excluded because their children had either food allergies or atopic disease (Fig. 1).

The median age of the 202 children in the food allergy group was 5 years (range, 1-17 years), 121 (60\%) were boys and 136 (67\%) were white European; 53\% had a history of allergic reactions to peanuts or tree nuts, 38\% to milk, and 37\% to egg. One hundred and twelve (55\%) had a history of allergic reactions to multiple food groups. Fifty-seven children with food allergies (28\%) had experienced breathing problems with previous allergic reactions, and $14(7 \%)$ had felt faint. Seventy children (35\%) had been prescribed an EAI, and $8(4 \%)$ had used their autoinjector to treat a previous reaction. Eighty children (40\%) had asthma, 
Table 2 Multivariate analysis of factors associated with parents' perceived risk of their child sustaining future allergic reactions to foods*\#

Cofactors High Perceived Chance by Parents of

\begin{tabular}{|c|c|c|c|c|c|c|c|c|}
\hline & \multicolumn{2}{|c|}{$\begin{array}{c}\text { Eating a Food To } \\
\text { Which the Child Is } \\
\text { Allergic }\end{array}$} & \multicolumn{2}{|c|}{$\begin{array}{l}\text { A Serious Future } \\
\text { Allergic Reaction }\end{array}$} & \multicolumn{2}{|c|}{$\begin{array}{l}\text { Death from a Future } \\
\text { Allergic Reaction }\end{array}$} & \multicolumn{2}{|c|}{$\begin{array}{c}\text { Able to Manage a } \\
\text { Future Allergic } \\
\text { Reaction }\end{array}$} \\
\hline & $\operatorname{RR}(95 \% \mathrm{CI})$ & $p$ Value & RR $(95 \%$ CI) & $p$ Value & RR $(95 \%$ CI $)$ & $p$ Value & RR (95\% CI) & $p$ Value \\
\hline Mother vs father & $3.7(1.0-13.9)$ & 0.06 & $1.0(0.4-2.4)$ & 0.9 & $2.3(0.4-12.5)$ & 0.3 & $1.1(0.1-15.5)$ & 0.9 \\
\hline $\begin{array}{c}\text { White European vs } \\
\text { other ethnicity }\end{array}$ & $1.3(0.6-2.6)$ & 0.5 & $0.9(0.5-1.9)$ & 0.8 & $2.1(0.8-5.7)$ & 0.1 & $1.2(0.4-4.4)$ & 0.7 \\
\hline $\begin{array}{l}\text { University } \\
\text { education }\end{array}$ & $1.2(0.6-2.3)$ & 0.7 & $0.9(0.5-1.7)$ & 0.8 & $0.3(0.1-0.7)$ & 0.01 & $1.0(0.2-4.1)$ & 0.1 \\
\hline Age of child & $1.0(0.9-1.1)$ & 0.6 & $0.9(0.9-1.0)$ & 0.3 & $1.0(0.9-1.1)$ & 0.5 & $0.9(0.7-1.1)$ & 0.3 \\
\hline Son vs daughter & $0.6(0.3-1.3)$ & 0.2 & $1.5(0.8-2.9)$ & 0.2 & $0.9(0.4-2.4)$ & 0.9 & $1.7(0.4-6.8)$ & 0.4 \\
\hline $\begin{array}{l}\text { Nuts vs other } \\
\text { allergen }\end{array}$ & $0.5(0.2-1.1)$ & 0.1 & $1.6(0.8-3.5)$ & 0.1 & $0.9(0.3-2.6)$ & 0.8 & $1.3(0.3-6.1)$ & 0.7 \\
\hline $\begin{array}{l}\text { Multiple allergen } \\
\text { groups }\end{array}$ & $0.9(0.4-1.8)$ & 0.7 & $1.2(0.6-2.4)$ & 0.5 & 6) & 1.0 & $0.1(0.0-0.6)$ & 0.01 \\
\hline $\begin{array}{l}\text { Anaphylaxis vs } \\
\text { milder reaction }\end{array}$ & $1.4(0.6-3.1)$ & 0.4 & $2.6(1.3-5.5)$ & 0.01 & $1.6(0.6-4.5)$ & 0.3 & $0.7(0.2-3.5)$ & 0.7 \\
\hline History of asthma & $1.0(0.5-2.2)$ & 0.9 & $1.6(0$ & 0.2 & $0.5(0.2-1.6)$ & 0.3 & $0.8(0.2-3.4)$ & 0.7 \\
\hline $\begin{array}{l}\text { Possession of an } \\
\text { autoinjector }\end{array}$ & $0.8(0.4-1.8)$ & 0.6 & $2.6(1.2-5.5)$ & 0.01 & $9.9(3.3-30)$ & $<0.001$ & $2.5(0.4-11.9)$ & 0.4 \\
\hline Autoinjector used & $3.1(0.6-16.3)$ & 0.2 & $0.9(0.1-6.3)$ & 0.9 & $0.2(0.0-1.7)$ & 0.1 & $0.1(0.0-2.9)$ & 0.2 \\
\hline $\begin{array}{l}\text { HADS depression } \\
\text { score }\end{array}$ & $1.1(0.9-1.2)$ & 0.4 & & 0.2 & $1.0(0.8-1.2)$ & 0.2 & $0.8(0.6-1.1)$ & 0.2 \\
\hline $\begin{array}{l}\text { HADS anxiety } \\
\text { score }\end{array}$ & $1.1(0.9-1.2)$ & 0.3 & $1.1(0.9-1.2)$ & 0.4 & $1.2(1.1-1.4)$ & 0.02 & $1.3(1.0-1.6)$ & 0.06 \\
\hline OCIR score & $1.0(0.9-1.0)$ & 0.3 & $1.0(1.0-1.0)$ & 0.7 & $1.0(0.9-1.1)$ & 0.1 & $1.1(1.0-1.2)$ & 0.1 \\
\hline
\end{tabular}

$R R=$ Relative risk $; C I=$ confidence interval HADS $=$ Hospital Anxiety and Depression Scale; OCIR $=$ ObsessiveCompulsive Inventory-Revised.

${ }^{*}$ High risk (great, very great, or $100 \%$ chance of a future event) compared with lower risk $(0 \%$, very small, small, or fair chance of a future event).

\#Binary logistic covariant regression analysis with the addition of the variables.

and $48(24 \%)$ had previously been admitted to the hospital because of their asthma.

\section{Parents' Perceived Risk of their Child Experiencing Future Allergic Reactions}

Eighty-five percent of the questionnaires were completed by the mothers, $15 \%$ by the fathers. Demographic and psychological factors were not associated with the parents' perceived future risk of their child eating food to which they were allergic (Table 2). However, parents of children with a history of an anaphylactic reaction and those who possessed an EAI were 2.6 times more likely to consider their child at a high risk of a future "serious and/or anaphylactic" reaction. Three times as many parents who possessed an EAI $(12 / 70[18 \%])$ compared with those who did not have an EAI $(7 / 132[5 \%])$ believed that their child was at high risk of a future anaphylaxis (Fig. 2). Possessing an F2 EAI was the cofactor associated with the highest perceived risk of death from future allergic reactions (9.9 [95\% confidence interval $\{\mathrm{CI}\}, 3.3-30] ; p<0.001$ ) (Table 2). One percent of the parents without an EAI $(2 / 131)$ compared with $10 \%$ of the parents with an EAI $(7 / 70)$ believed that their child was at high risk of death from a future allergic reaction (Fig. 2). The parents with higher anxiety scores (1.2 [1.1-1.4]; $p=0.02)$ and parents without a university education (3.7 [1.4$10.1]) ; p<0.01$ ) perceived that their child was at a higher risk of death (Table 2). Nut allergy was not perceived by their parents as more likely to be associated with a high risk of serious or fatal anaphylaxis than allergies to other foods. Allergies to multiple foods was the only factor associated with parents' perception that they would not be able to manage 


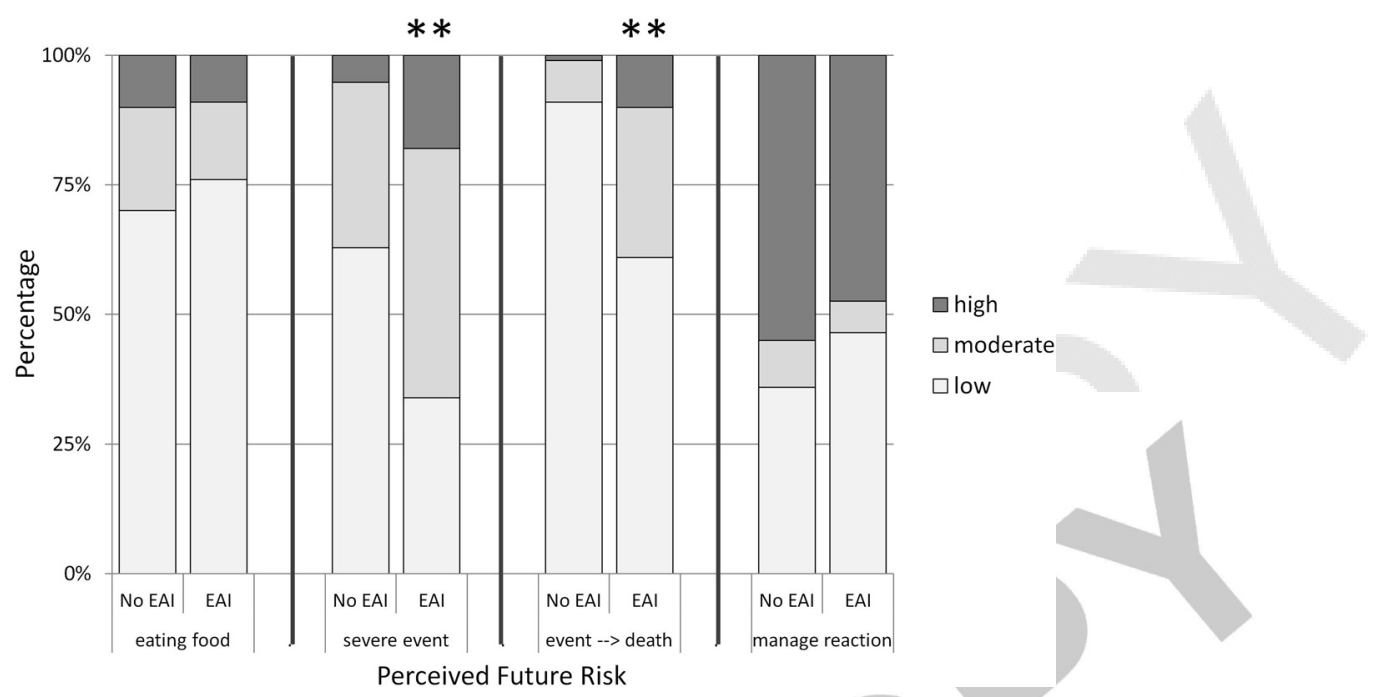

Figure 2. Possession of an epinephrine autoinjector (EAI) as a factor that influences parents' perceived risk of their child's having future allergic reactions. The first three panels from left to right show the parents' perception of the chance of their child (1) eating a food to which he or she is allergic, (2) having a serious allergic reaction, and (3) having a fatal allergic reaction. The final panel on the very right of the figure shows the parents" perception that they will be able to manage the future allergic reaction. A "low" score combines never ( $0 \%$ chance), very small chance, or small chance Food Allergy Independent Measure (FAIM) scores; "moderate" is equivalent to fair chance FAIM score; a "high" score combines great chance, very great chance, or always (100\% chance) FAIM scores. Comparisons are made by using $\chi^{2}$ statistics. $\mathrm{AQ}: 19$ (20): $* * 0.005$ (2-tailed test).

AQ: $\{$ pture reactions (relative risk [RR] 7.1 [95\% CI, 1.632]) (Table 2).

Because EAI possession was the main variable associated with a perceived risk of death from future anaphylaxis, further analyses that compared families with and those without EAI were performed AQ: $\bigcirc$ Table 3). Children who possessed EAI were signifcantly older (RR 1.1 [95\% CI, 1.0-1.2]); were more likely to have had an anaphylactic reaction (RR 2.2 [95\% CI, 1.1-4.6]), particularly to peanuts or tree nuts (RR 4.2 [95\% CI, 1.9-9.1]); and to have allergic rhinitis. There were no significant difference in parents' ethnicity, university education, or affect between the groups.

\section{Psychological Factors and Parents' Perceived Risk of Future Allergic Reactions in Children with Food Allergies}

The mothers $(n=249)$ did not differ significantly from the fathers $(n=44)$ in any of the three psychology scores. In addition, these scores were not significantly different in parents of different educational attainment (data not shown). However, the parents who perceived that their child was at a higher risk of future allergic reaction to foods were significantly more anxious (Fig. 3). Those parents who believed that there was a risk of anaphylaxis or death were also more likely to have significantly higher depression and obsessive-compulsive disease scores.
Clinical Features of the Injury Group and Comparison with the Food Allergy Group

Of the 91 children who attended an adjoining pediatric orthopedic clinic for accidental sprains and fractures, $73(80 \%)$ had sustained a fracture, $45 \%$ to a bone in their upper limb, $24 \%$ to their lower limb, and $2 \%$ to their pelvis or rib. Twenty-seven (30\%) required an operation for the fracture or dislocation. Thirty-four $(37 \%)$ had a history of an injury. The characteristics of children and their parents with food allergies and children and their parents with injuries are compared in Table 4. Children who presented with food allergies were significantly younger than those who presented with injuries (median age, 5 versus 10 years; $p>0.001$ ) and were more likely to be white European (67\% versus $52 \% ; p<0.01$ ). Operative treatment was the only factor associated with a significantly higher perceived risk by the parents of "any" (3.9[1.4-11.0]; $p=0.01)$ or "serious" future injury (7.6 [1.3-44]; $p=0.02)$. Only 1 of 91 parents (1\%) thought that there was a high chance of his or her child dying of a future injury. Parents' perceived impact of their child's allergy or injury on school life was similar, but parents whose children had had injuries believed that the injury had a significantly greater impact on the child's home and extracurricular activities (Fig. 4). In contrast, parents of children with food allergies were more likely to consider their children at risk of future serious or fatal events (Fig. 5). The perceived risk of a serious future adverse event was 13-fold higher in the group with food allergies than in 
Table 3 Characteristics of children with food allergies and of their parents based on EAI possession

\begin{tabular}{|c|c|c|c|}
\hline & No EAI $(n=132)$ & EAI $(n=70)$ & $p$ Value* \\
\hline Age, median (IQR), y & $4(2-8)$ & $8(4-11)$ & 0.001 \\
\hline Boys, no. $(\%)$ & $76(58)$ & $45(64)$ & 0.3 \\
\hline An only child, no. (\%) & $76(58)$ & $45(64)$ & 0.4 \\
\hline White European origin, no. (\%) & $89(67)$ & $47(67)$ & 1.0 \\
\hline Anaphylactic symptoms, no. (\%) & $26(20)$ & $31(44)$ & 0.001 \\
\hline EAI previous used, no. (\%) & $0(0)$ & $8(11)$ & 0.001 \\
\hline Peanut or tree nut allergy, no. (\%) & $51(39)$ & $55(79)$ & 0.001 \\
\hline Cow's milk protein allergy, no. (\%) & $53(24)$ & $23(33)$ & 0.2 \\
\hline \multicolumn{4}{|l|}{ Atopic diseases, no. $(\%)$} \\
\hline Atopic dermatitis & $110(83)$ & $48(69)$ & 0.02 \\
\hline Asthma & $46(35)$ & $34(49)$ & 0.07 \\
\hline Allergic rhinitis & $32(25)$ & $30(51)$ & 0.001 \\
\hline Questionnaire completed by the mother, no. (\%) & $109(83)$ & $66(94)$ & 0.03 \\
\hline Parents with university education, no. (\%) & $65(49)$ & $27(39)$ & 0.4 \\
\hline \multicolumn{4}{|l|}{ Parents' psychological profile, median (IQR) } \\
\hline HADS depression score & $4(1-7)$ & $3(1-6)$ & 0.7 \\
\hline HADS anxiety score & $5(2-9)$ & $6(4-8)$ & 0.3 \\
\hline OCD score & $7(3-15)$ & $6(4-12)$ & 0.6 \\
\hline
\end{tabular}

$E A I=$ Epinephrine autoinjector; $I Q R=$ interquartile range; HADS = Hospital Anxiety and Depression Scale; OCD = Obsessive-compulsive disease.

${ }^{*}$ Compared patients who had and patients who had not been prescribed an EAI.

\#Anaphylaxis is defined as allergic reactions associated with respiratory or circulatory symptoms.

$\S S t a t i s t i c a l$ analysis was performed by using either the $\chi^{2}$ test for discrete variables or the Mann-Whitney U test for continuous variables.

those with injuries $(p<0.001)$, independent of the age of the child and the ethnicity of the parent.

\section{DISCUSSION}

AQ: 13 D our knowledge, this is the first study to quantify parents' risk perception of their child with serious or fatal allergic reactions to food. Half of the parents in this cohort believed that there was a moderate-to-high risk of their child having future anaphylaxis, and a fifth believed that their child had a moderate-to-high chance of dying from anaphylaxis. Previous anaphylaxis and possession of an EAI were two factors independently associated with a higher perceived risk of future anaphylaxis, after adjusting for confounders, such as the child's age, type of food allergen, parents' affect, and education, by using multivariate analysis. Peanut and/or tree nut allergy and a history of asthma were not associated with a higher perceived risk, even though there is published evidence for a link. ${ }^{31,32}$ The observed differences between the outcomes of our study and previous studies may relate to the measures used. We assessed parental risk perception, whereas others examined parental burden and/or QoL.17,19 King et al., ${ }^{33}$ examined the impact of peanut allergy on AQ: 1 20 L and anxiety in 46 families but used SCAS or STAI rather than the Hospital Anxiety and Depression Scale to assess anxiety and found that the mothers had worse QoL and anxiety scores than the fathers. Although we found no significant difference in anxiety scores of the mothers and fathers, the $p$ value was 0.055 , and a larger sample number may have shown a significant trend. Another study, which compared parents in the Netherlands and the United States, showed that, although American parents were more likely to visit a physician for their child's food allergies and had a better knowledge of food avoidance strategies than the Dutch parents, the U.S. parents had lower QoL scores. ${ }^{34,35}$

Parents who thought that their child was at a high risk of dying from anaphylaxis were less likely to be university educated. They also tended to have higher anxiety scores. A possible explanation for the latter observation is that having a child with food allergies makes parents more anxious. Gillespie et al. ${ }^{36}$ in an interview-based study, indicated that consultation with an allergy specialist may indeed initiate or heighten maternal anxiety about the impact of their child's food allergies. Alternatively, more anxious parents might worry more about the risks of food allergies, but, if this were the case, then one might expect that they might also request and receive EAIs from their child's physician. Our study found that parents in possession of an EAI were not more anxious than those without an autoinjector. 

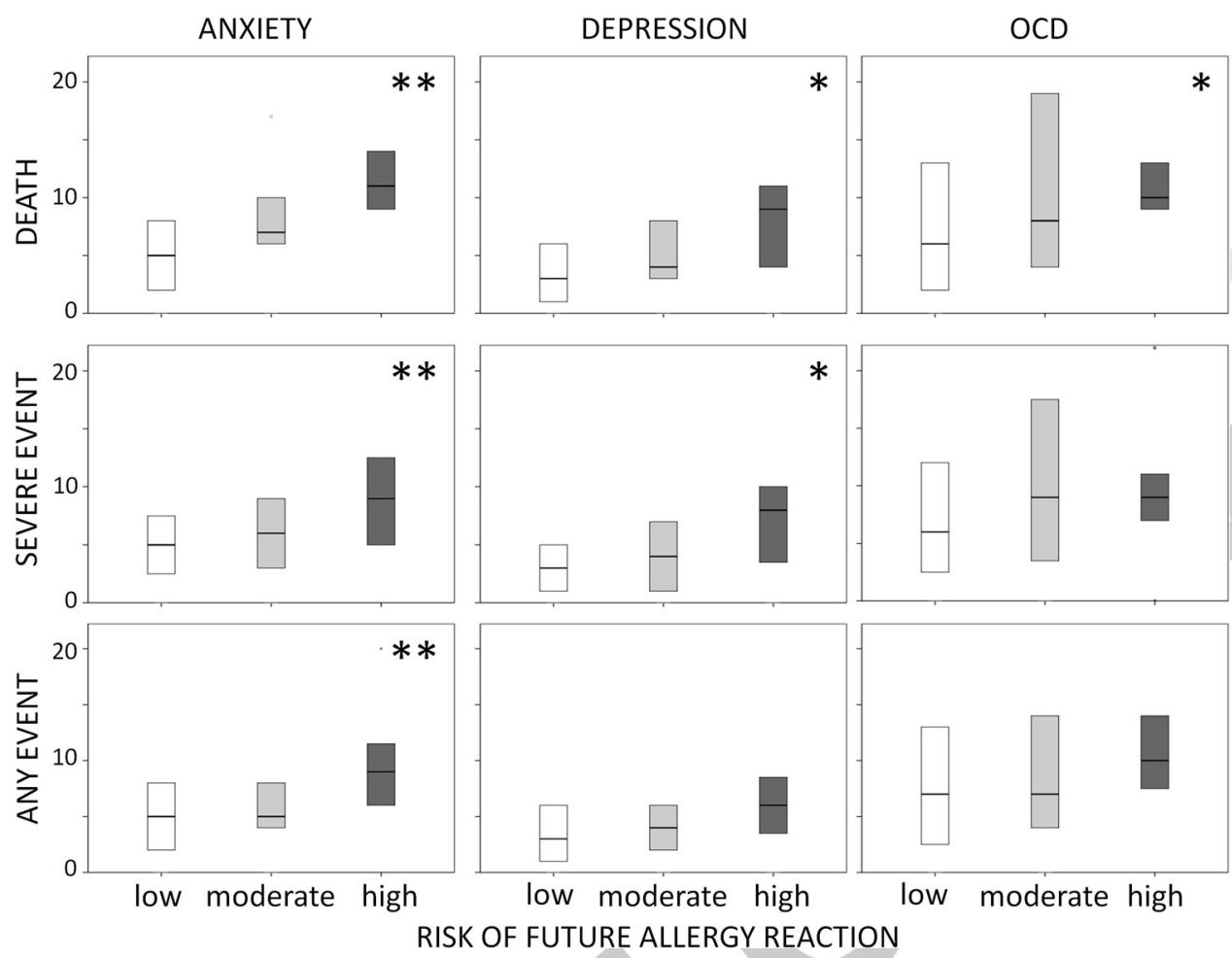

Figure 3. The association between the parents' affect and obsessive-compulsive disease (OCD) scores and the perceived risk that their child with a food allergy will have a future allergic reaction. The Hospital Anxiety and Depression Scale anxiety and depression scores as well as obsessive-compulsive scores of parents in relation to their perception that the child was at future risk of death (top panels), of a serious adverse event (middle panels), or of eating something to which he or she is allergic (lower panels). Data are shown as box plots (median and interquartile ranges) for low risk, moderate-to-fair risk, and high risk bars. Comparisons were made between median scores of parents who perceived a low and moderate or a high risk of future events for their children by using Kruskal-Wallis tests. ${ }^{*} p<0.05,{ }^{* *} p<0.005$ (2-tailed test).

EAIs are prescribed to treat anaphylaxis that could potentially, albeit rarely, lead to death. ${ }^{37,38}$ Our criteria for EAI prescribing, detailed in the Methods section, are more limited than those indicated in the 2015 U.S. anaphylaxis practice parameter update. ${ }^{39}$ These practice parameters not only recommend EAI for all patients who have experienced or are at risk for foodinduced anaphylaxis (including patients with food allergy and asthma; patients allergic to peanut, tree nuts, fish, and shellfish; and patients with a history of a systemic reaction to food) but also indicated that consideration be given to prescribing EAIs to all paAQ: $\bigcirc$ ents with immunoglobulin E-mediated food allergy. Our study indicated that parents who possessed EAI not only perceived that their child was at risk of future AQ: 1 2 haphylactic reactions but of fatal reactions कy supported those of Pinczower et al. ${ }^{40}$ who, in a recent Australia survey of 103 parents of children with food allergies, found that EAI possession was associated with significantly worse food allergy-related QoL scores and contrasted to other reports that indicated that parents with EAI are more confident in managing allergic reactions. ${ }^{18}$ Poor confidence may relate to lack of hands-on experience and fear of using EAIs. ${ }^{41}$ Fur- ther studies are required to directly compare EAI competence and confidence in parents who had and parents who had not used an EAI to treat anaphylaxis.

Compared with the injury group, parents of children with food allergies were 13-fold more likely to consider that their child at a high risk of a future serious adverse event and 21-fold more likely to consider that their child may die because of a future adverse event, independent of the child's age, sex, and ethnicity. This was at odds with pediatric morbidity and mortality statistics, in which accidental injuries account for one-third of all emergency department visits and are the most common cause of death in school-age children and young people worldwide, ${ }^{42,43}$ whereas allergic reactions to food accounts for $<1 \%$ of visits to emergency departments ${ }^{44,45}$ and only one to two childhood deaths in the United Kingdom each year. ${ }^{46}$ The reasons for using a group of children with bony injuries for comparison with children with food allergies deserves further clarification. First, both food-induced anaphylaxis and injuries are accidental. Second, as detailed above, accidental injuries are also potentially life threatening. Third, although not usually leading to chronic disease, injuries are potentially recurrent. The modified Food 
Table 4 Characteristics of children and their parents with food allergies and injuries

\begin{tabular}{|c|c|c|c|}
\hline & $\begin{array}{l}\text { Children with Food Allergies } \\
\qquad(n=202)\end{array}$ & $\begin{array}{l}\text { Children with Injuries } \\
\qquad(n=91)\end{array}$ & $p$ Value* \\
\hline Age, median (IQR), y & $5(3-9)$ & $10(7-12)$ & 0.001 \\
\hline Boys, no. $(\%)$ & $121(60)$ & $48(53)$ & 0.3 \\
\hline White European, no. (\%) & $136(67)$ & $47(52)$ & 0.01 \\
\hline \multicolumn{3}{|l|}{ Severity of allergy or injury, no. (\%) } & $\mathrm{N} / \mathrm{A}$ \\
\hline Anaphylaxis & $57(28)$ & - & \\
\hline \multicolumn{3}{|l|}{ Treatment given, no. (\%) } & $\mathrm{N} / \mathrm{A}$ \\
\hline Epinephrine & $8(4)$ & - & \\
\hline Operation & - & $27(30)$ & \\
\hline Cast and/or sling & - & $51(56)$ & \\
\hline \multicolumn{4}{|l|}{ Atopic diseases, no. (\%) } \\
\hline Atopic dermatitis & $158(78)$ & 0 & $\mathrm{~N} / \mathrm{A}$ \\
\hline \multicolumn{4}{|l|}{ Parents' psychological profile, median (IQR) } \\
\hline HADS depression score & $4(1-6)$ & $4(2-7)$ & 0.7 \\
\hline HADS anxiety score & $5(3-8)$ & $5(2-7)$ & 0.3 \\
\hline OCD score & $7(3-13)$ & $7(3-11)$ & 0.3 \\
\hline
\end{tabular}

$I Q R=$ Interquartile range; $N / A=$ not directly comparable or not applicable; HADS = Hospital Anxiety and Depression Scale; OCD $=$ Obsessive-compulsive disease.

${ }^{*}$ Compared patients with food allergies and those with injuries.

\#Anaphylaxis defined as reactions associated with respiratory or circulatory symptoms.

$\S$ Statistical analysis was performed by using either the $\chi^{2}$ test for discrete variables or the Mann-Whitney $U$ test for continuous variables.

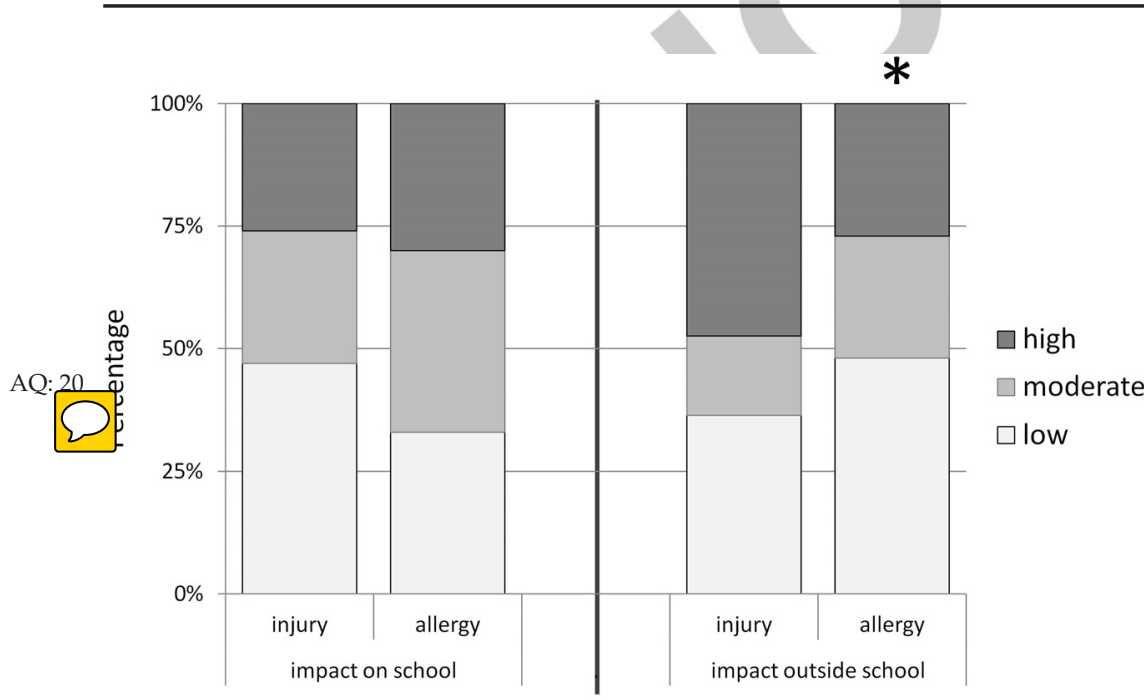

\section{Perceived Impact}

Allergy Independent Measure questionnaire for perception of the future risk of children with bony injuries has not been previously validated. However, of the observed trends in perceived risk of "any injury" $(28 \%)$, a "serious injury" (9\%), and "death" $(1 \%)$, the higher perceived impact of injuries on life outside of school compared with within school and the higher
Figure 4. The parents' perceived impact of their child's food allergy or injury on school and extracurricular activities. Assessment was made by using the Food Allergy Independent Measure (FAIM) assessment score (Zoa et al., 2002), or modification thereof. A "low" score combines almost none, very small, or little impact FAIM scores; a "moderate" score is equivalent to moderate and/or some impact FAIM scores; a "high" score combines great, very great, or extremely great impact FAIM scores. ${ }^{*} p<0.05, \chi^{2}$ test.

perceived risk in children who require an operation, all provided evidence for the validity of the questions.

\section{CONCLUSION}

It is understandable that some parents are unsure, concerned, or even overwhelmed by their child's food 
5. The parents' perceived risk of any, a serious, fatal future injury or allergic reaction to a food. Assessment was made by using the Food Allergy Independent Measure (FAIM) assessment score (Zoa et al., 2002) or modification thereof. A "low" score combines never ( $0 \%$ chance), very small chance, or small chance FAIM scores; "moderate" is equivalent to a fair chance FAIM score; a "high" score combines great chance, very great chance, or always (100\% chance) FAIM scores. ${ }^{* *} p<0.001, \chi^{2}$ test.

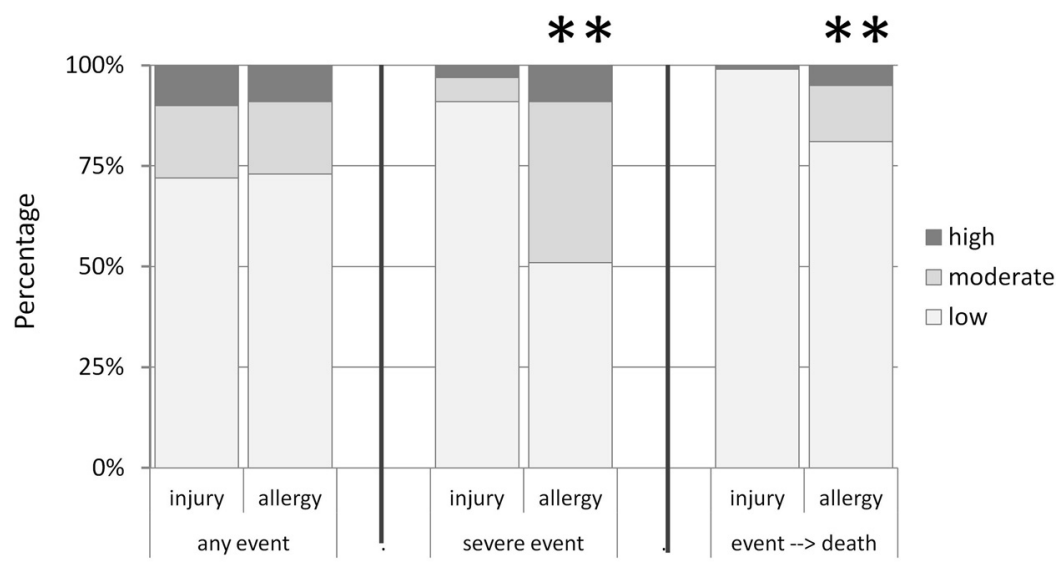

allergies. This study highlighted the discrepancy between perceived and actual risks that some parents have about their child with food allergies. Parents who are more anxious or have not been to university may need additional support to focus on the evidence, particularly with regard to the actual risk of dying from anaphylaxis and how to manage children with multiple allergies. A prescription of EAI should not only be accompanied by an explanation as to when and how to use the device but a clear explanation of the actual risks that physicians hope to avert by prescribing the device.

\section{ACKNOWLEDGMENTS}

The authors thank Timothy David, University of Manchester, Richard Pumphrey, honorary clinical immunologist, Manchester Royal Infirmary, and Allie Crewe, parent representative, for their helpful comments regarding this manuscript.

\section{REFERENCES}

1. Sicherer SH, and Sampson HA. Food allergy: Epidemiology, pathogenesis, diagnosis, and treatment. J Allergy Clin Immunol 133:291-307; quiz 308, 2014.

2. Mullins RJ, Dear KB, and Tang ML. Time trends in Australian hospital anaphylaxis admissions in 1998-1999 to 2011-2012. J Allergy Clin Immunol 136:367-375, 2015.

3. McGowan EC, Bloomberg GR, Gergen PJ, et al. Influence of early-life exposures on food sensitization and food allergy in an inner-city birth cohort. J Allergy Clin Immunol 135:171-178, 2015.

4. Liew WK, Williamson E, and Tang ML. Anaphylaxis fatalities and admissions in Australia. J Allergy Clin Immunol 123:434442, 2009.

5. Turner PJ, Gowland MH, Sharma V, et al. Increase in anaphylaxis-related hospitalizations but no increase in fatalities: An analysis of United Kingdom national anaphylaxis data, 19922012. J Allergy Clin Immunol 135:956-963, 2015.

6. Lau GY, Patel N, Umasunthar T, et al. Anxiety and stress in mothers of food-allergic children. Pediatr Allergy Immunol 25: 236-242, 2014.

7. Akeson N, Worth A, and Sheikh A. The psychosocial impact of anaphylaxis on young people and their parents. Clin Exp Allergy 37:1213-1220, 2007.

8. Primeau MN, Kagan R, Joseph L, et al. The psychological burden of peanut allergy as perceived by adults with peanut al- lergy and the parents of peanut-allergic children. Clin Exp Allergy 30:1135-1143, 2000.

9. Sicherer SH, Noone SA, and Munoz-Furlong A. The impact of childhood food allergy on quality of life. Ann Allergy Asthma Immunol 87:461-464, 2001.

10. Bollinger ME, Dahlquist LM, Mudd K, et al. The impact of food allergy on the daily activities of children and their families. Ann Allergy Asthma Immunol 96:415-421, 2006.

11. Gupta RS, Springston EE, Smith B, et al. Food allergy knowledge, attitudes, and beliefs of parents with food-allergic children in the United States. Pediatr Allergy Immunol 21:927-934, 2010.

12. Marklund B, Ahlstedt S, and Nordstrom G. Health-related quality of life in food hypersensitive schoolchildren and their families: Parents' perceptions. Health Qual Life Outcomes 10:4:48, 2006.

13. Simons FE, Ardusso LR, Dimov V, et al. World Allergy Organization Anaphylaxis Guidelines: 2013 update of the evidence base. Int Arch Allergy Immunol 162:193-204, 2013.

14. Muraro A, Werfel T, Hoffmann-Sommergruber K, et al. EAACI food allergy and anaphylaxis guidelines: Diagnosis and management of food allergy. Allergy 69:1008-1025, 2014.

15. Dhami S, Panesar SS, Roberts G, et al. Management of anaphylaxis: A systematic review. Allergy 69:168-175, 2014

16. Wang J, Young MC, and Nowak-Wegrzyn A. International survey of knowledge of food-induced anaphylaxis. Pediatr Allergy Immunol 25:644-650, 2014.

17. Sharma HP, and Herbert LJ. Food allergy: Psychosocial impact and public policy implications. Chem Immunol Allergy 101: 221-226, 2015.

18. Ravid NL, Annunziato RA, Ambrose MA, et al. Mental health and quality-of-life concerns related to the burden of food allergy. Psychiatr Clin North Am 38:77-89, 2015.

19. Saleh-Langenberg J, Goossens NJ, Flokstra-de Blok BM, et al. Predictors of health-related quality of life of European foodallergic patients. Allergy 70:616-624, 2015.

20. Howe L, Franxman T, Teich E, and Greenhawt M. What affects quality of life among caregivers of food-allergic children? Ann Allergy Asthma Immunol 113:69-74.e2, 2014.

21. Ward CE, and Greenhawt MJ. Treatment of allergic reactions and quality of life among caregivers of food-allergic children. Ann Allergy Asthma Immunol 114:312-318.e2, 2015.

22. Cummings AJ, Knibb RC, Erlewyn-Lajeunesse M, et al. Management of nut allergy influences quality of life and anxiety in children and their mothers. Pediatr Allergy Immunol 21:586-594, 2010.

23. Allen CW, Bidarkar MS, vanNunen SA, and Campbell DE. Factors impacting parental burden in food-allergic children. J Paediatr Child Health 51:696-698, 2015. 
24. Rouf K, White L, and Evans K. A qualitative investigation into the maternal experience of having a young child with severe food allergy. Clin Child Psychol Psychiatry 17:49-64, 2012.

25. Arkwright PD, Stafford JC, and Sharma V. Atopic dermatitis in children. J Allergy Clin Immunol Pract 2:388-395, 2014.

26. NIAID-Sponsored Expert Panel, Boyce JA, Assa'ad A, et al. Guidelines for the diagnosis and management of food allergy in the United States: Report of the NIAID-sponsored expert panel. J Allergy Clin Immunol 126(suppl.):S1-S58, 2010.

27. van der Velde JL, Flokstra-de Blok BM, Vlieg-Boerstra BJ, et al. Development, validity and reliability of the food allergy independent measure (FAIM). Allergy 65:630-635, 2010.

28. Zigmond AS, and Snaith RP. The hospital anxiety and depression scale. Acta Psychiatr Scand 67:361-370, 1983.

29. Bjelland I, Dahl AA, Haug TT, and Neckelmann D. The validity of the Hospital Anxiety and Depression Scale. An updated literature review. J Psychosom Res 52:69-77, 2002.

30. Foa EB, Huppert JD, Leiberg S, et al. The Obsessive-Compulsive Inventory: Development and validation of a short version. Psychol Assess 14:485-496, 2002.

31. Johnson J, Malinovschi A, Alving K, et al. Ten-year review reveals changing trends and severity of allergic reactions to nuts and other foods. Acta Paediatr 103:862-867, 2014.

32. Summers CW, Pumphrey RS, Woods CN, et al. Factors predicting anaphylaxis to peanuts and tree nuts in patients referred to a specialist center. J Allergy Clin Immunol 121:632-638, 2008.

33. King RM, Knibb RC, and Hourihane JO. Impact of peanut allergy on quality of life, stress and anxiety in the family. Allergy 64:461-468, 2009.

34. Le TM, Flokstra-de Blok BM, van Hoffen E, et al. Quality of life is more impaired in patients seeking medical care for food allergy. Int Arch Allergy Immunol 162:335-339, 2013.

35. Goossens NJ, Flokstra-de Blok BM, van der Meulen GN, et al. Food allergy knowledge of parents: Is ignorance bliss? Pediatr Allergy Immunol 24:567-573, 2013.
36. Gillespie CA, Woodgate RL, Chalmers KI, and Watson WT. "Living with risk": Mothering a child with food-induced anaphylaxis. J Pediatr Nurs 22:30-42, 2007.

37. Jerschow E, Lin RY, Scaperotti MM, and McGinn AP. Fatal anaphylaxis in the United States, 1999-2010: Temporal patterns and demographic associations. J Allergy Clin Immunol 134: 1318-1328.e7, 2014.

38. Pumphrey RS, and Gowland MH. Further fatal allergic reactions to food in the United Kingdom, 1996-2006. J Allergy Clin Immunol 119:1018-1019, 2007.

39. Lieberman P, Nicklas RA, Randolph C et al. Anaphylaxis-A practice parameter update 2015. Ann Allergy Asthma Immunol 115:341-384, 2015.

40. Pinczower GD, Bertalli NA, Bussmann N, et al. The effect of provision of an epinephrine autoinjector on quality of life in children with food allergy. J Allergy Clin Immunol 131:238-240, 2013.

41. Chad L, Ben-Shoshan M, Asai Y, et al. A majority of parents of children with peanut allergy fear using the epinephrine autoinjector. Allergy 68:1605-1609, 2013.

42. Sethi D, Towner E, Vincenten J, et al. European Report on Child Injury Prevention. Copenhagen: World Health Organization, 2008.

43. Wolfe I, MacFarlane $A$, Donkin $\mathrm{A}_{\text {, }}$ et al. Why ehildren die: Deaths in infants, children and young people in the UK. Arch Dis Child 100:907-914, 2015.

44. Melville N, and Beattie T. Paediatric allergic reactions in the emergency department: A review. Emerg Med J 25:655-658, 2008.

45. Braganza SC, Acworth JP, Mckinnon DR, et al. Paediatric emergency department anaphylaxis: Different patterns from adults. Arch Dis Child 91:159-163, 2006.

46. Umasunthar T, Leonardi-Bee J, Turner PJ, et al. Incidence of food anaphylaxis in people with food allergy: A systematic review and meta-analysis. Clin Exp Allergy 45:1621-1636, 2015.
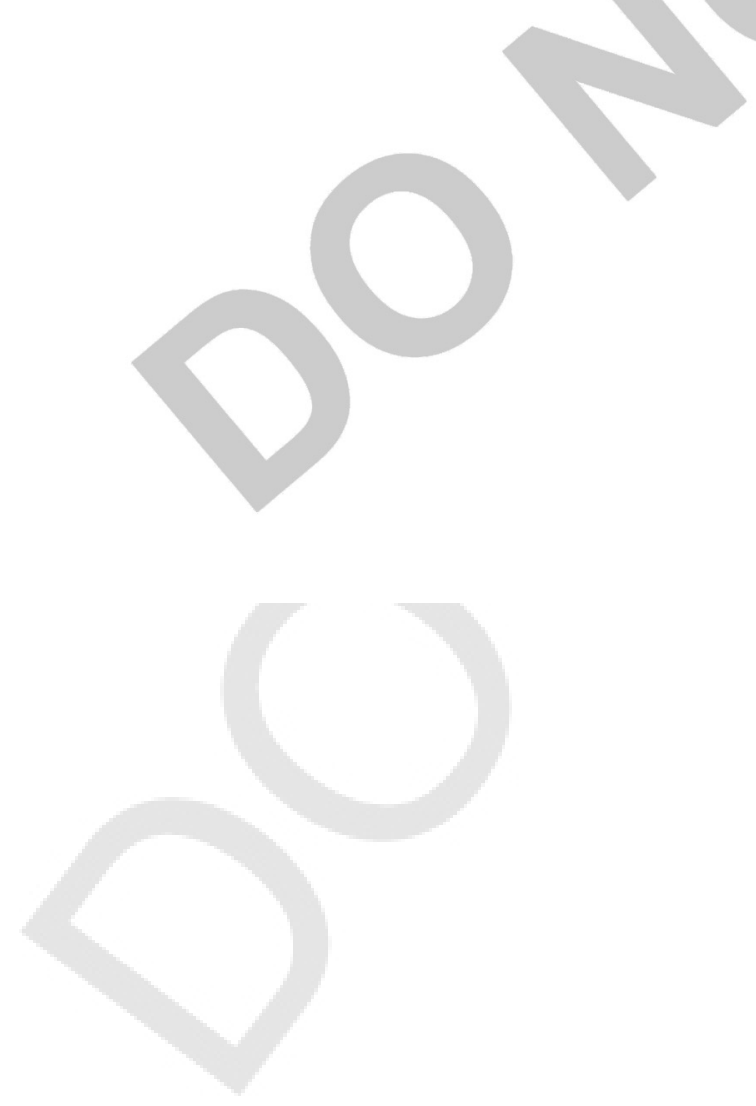


\section{AUTHOR QUERIES}

\section{AUTHOR PLEASE ANSWER ALL QERIES}

1-Au: Please check all author names for accuracy. For indexing purposes, please indicate the surname (family name) of each author. In addition, please confirm that authors are listed in the correct order and that all names are spelled correctly.

2-Au: Please verify. Okay to add "95\% confidence interval" for "1.7-53"

3-Au: In Table 1: Please note. Journal style is to not use highlighting. Please use bold and rephrase "Differences in wording between the two questionnaires are highlighted."

4-Au: Please add company information, including complete company name, city, and state (or country), for "IBM SPSS Statistics"

5-Au: In Table 2: Please clarify "Eating a food to which the child is allergic" is this "Of the child eating a food to which her or she is allergic" ? "A serious future allergic reaction" - is this "The child having a serious future allergic reaction" ? "Death from future allergic reaction" is this "The child's death from a future allergic reaction" ? "Able to manage future allergic reaction" - is this "Of being able to manage the child's future allergic reaction" ? Please indicate what the data in bold represent. Please verify. Are the footnote designators okay with the table title? Or, move to appropriate places within the table. Please note. Journal style indicates that $p$ cannot equal 0 . Okay as is?

6-Au: Please clarify. Is this "RR 9.9" ?

7-Au: Please verify. Is this "RR" and "95\% CI" - "1.2 [1.1-1.4]"

8-Au: Please verify. Is this "RR" and "95\% CI" - "3.7 [1.4-10.1]"

9-Au: Please move "relative risk" to first mention in the text if necessary.

10-Au: In Table 3: Please indicate what the data in bold represent. Please note. AMA Journal style indicates that $p$ cannot equal 1.0. Okay as is? Please verify. Please indicate where footnotes \# and $\S$ apply within the table.

11-Au: In Table 4: Please indicate what the data in bold represent. Please verify. Is $p=1.0$ okay as is ? Please indicate where the footnotes \# and § apply within the table.

12-Au: Please verify. Is this "RR: and "95\% CI" - "(1.4-11.0)" and "(1.3-44)"?

13-Au: Please verify. Okay to add "To our knowledge," ?

14-Au: Please spell out "SCAS" and "STAI"

15-Au: Please clarify. Is this "EAI" - "an autoinjector" ? 


\section{AUTHOR QUERIES}

\section{AUTHOR PLEASE ANSWER ALL QUERIES}

16-Au: Please verify. Okay as spelled out - "IgE" ?

17-Au: Please identify "They"

18-Au: Please note. This reference was not located in PubMed. Please verify/correct all information.

19-Au: Please clarify "Low"

20-Au: Please add a complete citation for "Zoa et al, 2002"

21-Au: Please add a complete citation for "Zoa et al, 2002"

22-Au: Please add department(s) and/or division(s) for affiliations 1 and 2.

23-Author: Please let us know the source of funding for your manuscript. Your article will be supplied to PMC if it's funded by NIH or any other federal agency.

24-Author: Please verify that this is your correct professional e-mail address. 